\title{
ANALISIS NILAI TAMBAH COKELAT BATANGAN (CHOCOLATE BAR) DI PIPILTIN COCOA, KEBAYORAN BARU, JAKARTA SELATAN
}

\author{
Vitalia Putri Asheri ${ }^{1}$, dan Amzul Rifin ${ }^{2)}$ \\ ${ }^{1,2)}$ Departemen Agribisnis, Fakultas Ekonomi dan Manajemen, Institut Pertanian Bogor \\ ${ }^{1)}$ puzzy_zahra@yahoo.com
}

\begin{abstract}
Indonesia is the third largest world cocoa producer. For years, cocoa bean from Indonesia has been exporter as raw beans. Domestic cocoa manufacturing industry is still dominated by international companies such as Nestle, Marz, JB Cocoa Malaysia, and others than domestic small and medium enterprise. This condition shows that value added of cocoa processing have not yet accepted by local entrepreneurs. Nowadays, most of the small and medium enterprise produce intermediate and compound chocolate products with low use of cocoa butter volume in proportion. Then, those intermediate products would be exported and will be reimported again by Indonesia as final product. Pipiltin Cocoa is the only small-scale natural chocolate producer in Indonesia using local cocoa bean from Bali and Aceh. This research focuses on value added analysis of bar chocolate in Pipiltin Cocoa produce which is important to conduct in order to know the added value made from a domestic small-scale cocoa farm producing original cocoa products.
\end{abstract}

Keyword(s): Cocoa beans, compound chocolate, chocolate industry, added value, chocolate bar

\begin{abstract}
ABSTRAK
Indonesia merupakan produsen biji kakao ketiga di dunia. Selama ini kakao Indonesia hanya diekspor dalam bentuk biji mentah. Industri pengolahan kakao menjadi produk turunan yaitu cokelat yang ada di dalam negeri masih dikuasai oleh perusahaan - perusahaan asing dan perusahaan besar multinasional seperti Nestle, Marz, dan JB Cocoa Malaysia dibandingkan usaha lokal skala kecil dan menengah. Kondisi ini yang menggambarkan bahwa nilai tambah belum dapat dinikmati oleh pelaku usaha domestik. Industri cokelat dalam negeri pun lebih banyak menghasilkan produk antara dan produk cokelat turunan (compound chocolate) dengan penggunaan lemak cokelat yang rendah proporsinya. Produk antara tersebut justru diekspor dan kembali diimpor oleh Indonesia dalam bentuk cokelat jadi. Pipiltin Cocoa merupakan satusatunya unit usaha skala kecil penghasil cokelat murni di Indonesia dan menggunakan biji kakao lokal yaitu dari Bali dan Aceh. Penelitian mengenai analisis nilai tambah produk cokelat batangan di Pipiltin Cocoa ini penting dilakukan untuk mengetahui gambaran nilai tambah usaha domestik skala kecil yang menghasilkan cokelat lokal murni.
\end{abstract}

Kata Kunci: Biji kakao, cokelat compound, industri cokelat, nilai tambah, cokelat batangan

\section{PENDAHULUAN}

Cokelat merupakan produk turunan dari industri pengolahan biji kakao. Penghasil biji kakao terbesar di dunia sampai tahun 2013 adalah negara Pantai Gading (1.480.000 ton) dan Ghana (850.000 ton), selanjutnya disusul oleh Indonesia (430.000). Saat ini kakao dunia 
diproduksi oleh Afrika dengan pangsa produksinya sebesar $73 \%$ dari produksi dunia, kemudian diikuti Asia dan Oceania sebesar 14\% dan Amerika sebesar 13\% (World Cocoa Foundation 2012).

Indonesia merupakan produsen biji kakao terbesar ketiga di dunia setelah Pantai Gading dan Ghana. Hal yang cukup mengganggu sampai saat ini adalah penggunaan biji kakao dalam negeri sebagai bahan baku industri pengolahan produk-produk turunan seperti lemak, bubuk, pasta cokelat, dan cokelat batangan masih sangat rendah. Pada Lampiran 1 terlihat bahwa produksi biji kakao Indonesia tahun 2010/2011 sebesar 440.000 ton, namun total grinding (pengolahan) hanya sebesar 190.000 ton, sisanya diekspor dalam bentuk biji mentah (Kementerian Pertanian 2011). Pada periode tahun 2010/2011 hingga 2012/2013 terlihat adanya peningkatan volume pengolahan biji kakao Indonesia. Perkiraan oleh ICCO (International Cocoa Organization 2013), total pengolahan biji kakao Indonesia tahun 2011/2012 bertambah menjadi 270.000 ton dan sebesar 255.000 ton pada tahun 2012/2013. Statistik data grinding biji kakao Indonesia dapat dilihat pada Lampiran 2.

Pada tahun 2010, pemerintah menerapkan kebijakan Bea Keluar (BK) terhadap ekspor biji kakao. Kebijakan ini diterapkan untuk menurunkan volume ekspor biji kakao mentah dan terus meningkatkan volume grinding biji kakao sebagai bahan baku industri dalam negeri. Berdasarkan penelitian Syadullah (2012), setelah pemberlakuan bea keluar tersebut, ekspor biji kakao menurun dan jumlah perusahaan pengolahan kakao meningkat. Perubahan signifikan juga terjadi pada volume ekspor biji kakao dan kakao olahan pada 2011. Akibat dari kebijakan ini ekspor biji kakao pada tahun 2010 menurun sebesar 6.868 ton (2 persen), sedangkan produk olahannya meningkat sebesar 20.516 ton (25 persen). Berita ini menyimpulkan bahwa kondisi agribisnis kakao dalam negeri sudah mulai menunjukkan upaya pemberian nilai tambah.

Dampak penerapan BK lainnya adalah adanya penggeseran penggunaan biji kakao dalam negeri sebagai bahan baku industri lokal yang terus meningkat sekaligus tumbuhnya industri-industri baru pengolah kakao. Pada tahun 2006, industri kakao dan cokelat masih berjumlah 21 unit, sedangkan saat ini terdapat peningkatan jumlah industri kakao dan cokelat menjadi 39 unit (Kementerian Pertanian 2013). Selain itu, perusahaan pengolah kakao dalam negeri juga terlihat meningkatkan kapasitas produksinya, bahkan beberapa pabrik cokelat yang sempat mati suri kembali beroperasi (Kementerian Perindustrian, 2012). Peningkatan jumlah industri kakao bukan parameter kuat terhadap kemajuan indusri kakao dalam negeri. Kakao dihasilkan mayoritas oleh petani rakyat, sebesar 89\%, disusul oleh swasta 5\%, dan perkebunan negara sebesar 6\% (Kementrian Perindustrian 2012). Oleh karena itu perlu diperhatikan apakah kemajuan indusri pengolahan kakao sudah menjamin dalam pembentukan kesejahteraan petani sebagai aktor utama penghasil biji kakao. Sebagian besar petani mampu mengolah 
kakaonya dalam suatu industri kecil dan menengah. Sedangkan meningkatnya industri kakao didominasi oleh peran perusahaan asing atau multinasional.

Perkembangan industri pengolahan kakao dalam negeri belum mempunyai pengaruh yang signifikan dalam mendorong munculnya industri pengolahan kakao skala kecil dan menengah. Pada tahun 2011, muncul pabrik pengolahan kakao baru di Batam oleh investor asal Malaysia yaitu PT. Asia Cocoa Indonesia. Sedangkan tahun 2013, pabrik asing lainnya mulai masuk dan beroperasi di Indonesia seperti JB Cocoa asal Malaysia, Mars dan Cargil asal AS, dan Nestle asal Swiss (Asosiasi Industri Kakao Indonesia, 2013). PT Nestle melakukan ekspansi pabrik susu Milo dan Dancow di Pasuruan dan Karawang. Pabrik-pabrik ini memproduksi produk perantara industri hilir seperti bubuk cokelat yang kemudian dikirim ke negara asli untuk diolah menjadi cokelat.

Cokelat atau produk turunan cokelat dari negara-negara tersebut kemudian diekspor kembali ke Indonesia. Sedangkan cokelat yang telah dikenal didalam negeri seperti Silverqueen, Delfi, Cadburry, merupakan cokelat lisensi perusahaan luar negeri meskipun proses produksi dilakukan di Indonesia. Industri kecil dan menengah pengolahan biji kakao masih kalah bersaing dengan perusahaan asing tersebut.

Produk cokelat hasil industri menengah merupakan cokelat compound yaitu jenis cokelat dengan proporsi penggunaan lemak cokelat yang sangat rendah (adanya kombinasi antara lemak cokelat dengan lemak nabati). Selain itu, saat ini Indonesia belum mempunyai produk cokelat unggulan hasil produksi industri kecil dan menengah. Hal ini memberikan pelajaran besar bahwa kemajuan industri kakao dalam negeri hanya kemajuan perusahaan asing yang berhasil menanamkan investasinya didalam negeri. Indonesia masih menggantungkan industri hilir kakaonya kepada perusahaan asing dan itu artinya nilai tambah hasil olahan kakao masih dirasakan oleh produsen luar dan Indonesia masih berperan sebagai penyedia bahan baku saja.

Lambatnya pengembangan industri pengolahan kakao skala kecil dan menengah perlu diidentifikasi faktorfaktor penyebabnya. Salah satu faktor yang dapat dianalisis adalah nilai tambah. Nilai tambah yang besar sebagai ukuran keutungan kotor produsen menjadi satu faktor pemicu perkembangan Usaha Kecil Menengah (UKM) pengembangan cokelat. Berdasarkan uraian diatas, menarik untuk diteliti apakah nilai tambah pengolahan kakao menjadi cokelat oleh UKM selama ini masih rendah sehingga industri pengolahan kakao menjadi cokelat masih didominasi oleh perusahaan besar dan asing. Harapan terhadap majunya industri pengolahan kakao dalam negeri muncul dari Pipiltin Cocoa.

Berdasarkan survey (2013), Pipiltin Cocoa merupakan satu-satunya unit bisnis skala menengah penghasil produk cokelat batangan dari lemak cokelat 100\% dengan biji kakao asli Indonesia yaitu dari Bali dan Aceh.

Pemilik Pipiltin adalah warga domestik yang memahami dengan baik 
kondisi agribisnis kakao Indonesia. Pipiltin mengolah biji kakao lokal dari Aceh dan Bali menjadi cokelat asli. Motivasi utama pemilik adalah mendirikan suatu perusahaan pengolahan kakao lokal menjadi produk cokelat dengan kualitas tinggi layaknya cokelat-cokelat luar negeri. Dari uraian ini, menarik untuk diteliti besarnya nilai tambah industri cokelat “ Pipiltin Cocoa” sebagai bahan informasi bagi seluruh stakeholder agribisnis kakao khususnya pemerintah dalam mengembangkan industri cokelat.

Adapun tujuan penelitian adalah mengkaji nilai tambah cokelat di Pipiltin Cocoa dengan fokus pada produk cokelat utama yaitu cokelat batangan (chocolate bar).

\section{METODE PENELITAN}

Penelitian dilakukan dengan metode survey dengan memilih tempat penelitian yaitu Pipiltin Cocoa secara sengaja (purposive sampling) dengan pertimbangan pada kriteria perusahaan asli Indonesia yang menghasilkan produk cokelat converture (real cokelat) dengan kualitas cokelat tinggi dan memenuhi kriteria untuk pemasaran internasional serta berbahan baku lokal. Penelitian ini dilakukan pada bulan Desember 2013 sampai Januari 2014.

Jenis data yang digunakan dalam penelitian ini adalah data primer dan data sekunder. Data Primer yang digunakan berupa hasil pengajuan pertanyaan melalui wawancara secara langsung kepada pihak manajemen. Sedangkan data sekunder yang digunakan adalah statistik data-data terkait dalam penelitian ini. Dalam pengolahan dan analisis data, metode yang digunakan dalam penelitian adalah analisis kuantitatif dengan metode Hayami.

\section{HASIL DAN PEMBAHASAN}

Analisis nilai tambah yang digunakan dalam penelitian ini dimulai dari pengadaan bahan baku yaitu biji kakao fermentasi hingga menjadi produk coklat siap konsumsi. Penelitian ini berfokus pada produk cokelat utama yaitu cokelat batangan (chocolate bar). Komposisi coklat batangan ini adalah 84 persen real cokelat. Kandungan 84 persen ini diartikan bahwa berdasarkan kandungan dalam satuan gram, cokelat bar yang dijual dalam kemasan dengan berat 100 gram terdiri dari 84 gram cocoa butter dan sisanya adalah bahan baku tambahan yakni gula dan susu. Bahan baku yang digunakan adalah biji kakao fermentasi yang diambil langsung dari kelompok petani kakao di Aceh.

Setiap periode produksinya, Pipiltin Cocoa mengolah $30 \mathrm{~kg}$ biji kakao dan membutuhkan waktu empat hari hingga menjadi cokelat bar yang siap dikonsumsi. Dalam $30 \mathrm{~kg}$ input yang digunakan, sebesar $26 \mathrm{~kg}$ akan terbentuk menjadi cokelat. Jika dihitung per hari, Pipiltin memproduksi cokelat batangan setiap harinya sebesar 6,5 kg. Dasar perhitungan dalam analisis nilai tambah kegiatan pengolahan biji kakao ini menggunakan per satuan kilogram per biji kakao sebagai bahan baku utama. Harga biji kakao fermentasi yang diterima Pipiltin dari Aceh adalah Rp 44.000 per kg, sedangkan biaya bahan baku tambahannya yaitu gula dan susu secara akumulatif adalah sebesar Rp 
6.000 per kg. Harga jual cokelat batangan ini adalah Rp 40.000 per 100 gram atau Rp 400.000 per kg.

Dalam setiap proses produksi, Pipiltin menggunakan tiga orang karyawan setiap harinya selama delapan jam waktu bekerja. Jika dikonversikan dalam satuan HOK, Pipiltin Cocoa menggunakan tenaga kerja sebanyak $3 \mathrm{HOK}$ per periode produksi dimana $1 \mathrm{HOK}$ adalah delapan jam. Setiap harinya tenaga kerja ini diberikan insentif (upah) sebesar Rp 67.000 per HOK.

Berdasarkan hasil pembagian besaran total output per input bahan baku utama didapatkan nilai faktor konversi sebesar 0,87. Nilai ini menunjukan bahwa setiap satu kilogram biji kakao yang diolah akan menghasilkan chocolate bar sebesar $0,87 \mathrm{~kg}$. Nilai koefisien tenaga kerja diperoleh dari hasil pembagian antara jumlah total tenaga kerja (HOK) selama satu periode produksi dengan jumlah input bahan baku yang diolah dalam satu hari. Hasil perhitungan tersebut menunjukan bahwa nilai koefisien tenaga kerja pada industri coklat “ Pipiltin Cocoa” adalah sebesar 0,4 . Nilai ini dapat diinterpretasikan sebagai jumlah hari orang kerja (HOK) yang diperlukan untuk mengolah $1 \mathrm{~kg}$ biji kakao menjadi chocolate bar adalah 0,4 HOK ( 1 HOK = 8 jam kerja). Jumlah hari orang kerja akan semakin rendah ketika perusahaan menambah volume produksi. Sumbangan input lain adalah biaya-biaya yang juga dikeluarkan perusahaan selain biaya bahan baku utama dan tenaga kerja langsung.

Sumbangan input lain yang digunakan adalah berupa susu dan gula.
Nilai total susu dan gula yang digunakan oleh Pipiltin Cocoa dalam penggunaan 30 kg biji kakao adalah sebesar Rp 180.000. Nilai tersebut kemudian dibagi dengan jumlah input bahan baku utama yang digunakan sehingga diperoleh sumbangan input lain per satuan kg biji kakao sebesar Rp 6.000.

Nilai output cokelat diperoleh dari hasil perkalian harga output per $\mathrm{kg}$ dengan faktor konversi. Nilai output chocolate bar Pipiltin Cocoa yang diproduksi yaitu sebesar Rp 348.000. Berdasarkan nilai output ini, Pipiltin Cocoa memperoleh nilai tambah sebesar $\mathrm{Rp}$ 298.000 dengan rasio nilai tambah 85,63 persen. Nilai ini dapat diinterpretasikan bahwa 85,63 persen dari nilai output merupakan nilai tambah pengolahan kakao menjadi cokelat. Nilai tambah disini merupakan nilai tambah kotor karena belum memperhitungkan imbalan tenaga kerja. Nilai tambah yang tinggi diperoleh Pipiltin karena harga jual output yang besar yakni Rp 40.000 per 100 gram cokelat atau Rp 400.000 per kg cokelat batangan.

Selain itu, biaya bahan baku lain dalam pengolahan kakao ini tidak terlalu besar yang hanya meliputi biaya untuk gula dan susu sebagai input tambahan. Jika dikaji lebih mendalam, industri cokelat yang mengutamakan cokelat asli khususnya dark cokelat akan memberikan nilai tambah cenderung memberikan nilai tambah cukup tinggi. Hal ini disebabkan oleh penggunaan input tambahan dalam proporsi sangat rendah. Imbalan tenaga kerja merupakan perkalian dari koefisien tenaga kerja dengan upah rata-rata tenaga kerja per HOK. Tingkat upah tenaga kerja 
adalah sebesar Rp 67.000 per HOK dengan pangsa tenaga kerja sebesar 8,89 persen. Hal ini berarti 8,99 persen dari nilai tambah sebesar Rp 298.000 merupakan imbalan yang diterima oleh tenaga kerja yaitu sebesar Rp 26.800 per hari atau 8 jam kerja. Kontribusi bagi tenaga kerja terhadap nilai tambah akan semakin kecil apabila perusahaan menambah volume produksinya. Sedangkan kapasitas perusahaan cokelat yang meningkat akan menurunkan biaya produksi.

Produk chocolate bar yang dihasilkan Pipiltin Cocoa ini berhasil memberikan keuntungan sebesar Rp 271.200 per kg. Keuntungan ini dihitung berdasarkan selisih antara nilai tambah dengan imbalan tenaga kerja. Dengan demikian, nilai dari keuntungan ini merupakan manfaat bersih yang diterima pemilik industri karena sudah menghitung pengeluaran untuk tenaga kerja selain dari pada biaya input utama dan tambahan. Keuntungan yang cukup tinggi ini berhasil diperoleh Pipiltin karena besarnya nilai tambah. Dengan demikian semakin besar nilai tambah suatu industri pengolahan komoditas pertanian maka berdampak positif terhadap keuntungan yang akan diterima. Tingkat keuntungan sebesar 91 persen diartikan bahwa 91 persen dari nilai tambah merupakan keuntungan bersih karena sudah memperhitungkan imbalan tenaga kerja.

Selain nilai tambah dan keuntungan pemilik industri, didalam metode Hayami juga tercakup bagaimana menghitung margin. Nilai margin diperoleh dari selisih antara nilai output dengan nilai bahan baku utama. Margin ini berbeda dengan nilai tambah karena dalam nilai tambah akan diperhitungkan nilai bahan baku tambahan sedangkan margin hanya memperhatikan nilai bahan baku utama.

Setelah diperoleh margin yang merupakan nilai tambah kotor, pemilik harus menghitung rate balas jasa untuk input tambahan, tenaga kerja, dan keuntungan pemilik dari nilai margin yang diperoleh. Berdasarkan hasil analisis nilai tambah diketahui bahwa margin dari pengolahan 1 kg biji kakao menjadi produk chocolate bar adalah sebesar Rp 304.000. Margin ini kemudian didistribusikan menjadi imbalan bagi tenaga kerja, sumbangan input lainnya, serta keuntungan perusahaan. Sebesar 8,82 persen dari nilai margin merupakan balas jasa untuk tenaga kerja, kemudian 1,97 persen untuk sumbangan input lainnya, dan distribusi margin bagi keuntungan perusahaan sebesar 89,21 persen.

Hasil penelitian menunjukan bahwa nilai tambah pengolahan biji kakao menjadi chocolate bar adalah sebesar Rp 298.000 per kg biji kakao yang digunakan. Sedangkan balas jasa terhadap faktor-faktor produksi atau margin adalah Rp 304.000 per kg biji kakao. Jika periode produksi per empat hari menggunakan 30 kg biji kakao maka dalam satu bulan kapasitas produksi Pipiltin adalah 225 kg biji kakao. Berdasarkan perhitungan per bulan, Pipiltin menerima nilai tambah dari proses produksi cokelat tersebut adalah sebesar Rp 67.050.000. Nilai ini diperoleh dari hasil perkalian antara volume penggunaan bahan baku per bulan dengan nilai tambahnya. Sedangkan untuk margin, perusahaan menerima margin sebesar Rp 68.400.000 yang merupakan 
hasil perhitungan dari Rp 304.000 per kg dikalikan 225 kg. Berdasarkan perhitungan nilai tambah industri kakao yang telah dijelaskan dalam tinjauan pustaka, nilai yang dihasilkan untuk Pipiltin Cocoa dengan nilai tambah pada cokelat batangan per bulan yaitu sebesar Rp 67.050.000 ini jauh lebih tinggi dibandingkan industri kakao seperti UKM Putri Willis di Madiun. Putri Willis menerima nilai tambah per bulan untuk produk pasta, lemak, dan bubuk cokelat berturut-turut adalah Rp 36.780.750, Rp 7.893.450, dan Rp 2.562.300. Sedangkan jika UKM Putri Willis mendiversifikasi produk olahannya yaitu bubuk dan lemak cokelat dalam satu kali produksi, nilai tambah yang dihasilkan lebih besar yaitu Rp 67.155.750. Nilai tersebut akan sebanding apabila Industri Cokelat seperti Pipiltin menghasilkan jenis cokelat yang lebih banyak. Keadaan ini dapat disimpulkan bahwa industri cokelat memiliki nilai tambah yang lebih besar dibanding industri kakao. Namun, nilai tambah akan lebih besar apabila masingmasing industri dapat menghasilkan beragam produk olahan dengan jumlah bahan baku yang sama. Proporsi hasil nilai tambah pengolahan biji kakao menjadi beragam produk antara telah diteliti oleh Dilana (2012) dengan hasil nilai tambah per $100 \mathrm{~kg}$ biji kakao untuk produk antara seperti pasta cokelat, bubuk, dan lemak cokelat berturut-turut sebesar Rp 16.347, Rp 5.847, Rp 2.847, dan Rp 29.847 untuk produk bubuk dan lemak dalam satu kali pengolahan (Lampiran 3).

Berdasarkan nilai tambah yang telah dihitung, perusahaan cokelat converture seperti Pipiltin menerima pendapatan yang lebih besar dibandingkan industri cokelat compound. Berdasarkan nilai marginnya, Pipiltin cocoa menerima margin sebesar Rp 68.400.000 per bulan dari penjualan cokelat batangannya. Nilai ini jauh lebih besar dibandingkan pendapatan yang diterima oleh KUB Sibali Resoe sebagai industri cokelat compound seperti yang telah dibahas dalam tinjauan pustaka, yaitu Rp 7.000.000 per bulan. Margin ini dapat dibandingkan dengan pendapatan karena hasil perhitungan margin diatas berdasarkan nilai output dikurangi dengan nilai bahan baku yang dikeluarkan. Ironisnya, nilai pendapatan KUB Sibali Resoe ini merupakan pendapatan kotor karena dihitung berdasarkan jumlah produksi perbulan dan harganya. Dengan demikian, jika dikurangkan dengan biaya bahan baku maka nilainya akan lebih rendah. Selain itu, harga cokelat batangan Sibali Resoe adalah Rp 1.500 per $30 \mathrm{~g}$ atau sekitar Rp 5.000 per 100 gram. Nilai ini berbeda jauh dengan harga produk cokelat batangan Pipiltin Cocoa yaitu Rp 40000 per 100 gram. Harga yang murah ini disebabkan karena jenis produk yang dihasilkan adalah cokelat compound yang menggunakan proporsi lemak cokelat sangat rendah. Hal ini berbeda dengan Pipiltin Cocoa yang sangat mengutamakan kualitas cokelat yang dihasilkan melalui penggunakan lemak cokelat seluruhnya dan tanpa tambahan lemak nabati. Perbedaan nilai ini membuktikan bahwa pengetahuan pemilik dan jenis cokelat yang dihasilkan memberikan pengaruh yang cukup signifikan terhadap pendapatan pemilik perusahaan cokelat. 
Total investasi pendirian KUB Sibali Resoe, suatu perusahaan pengolah biji kakao milik kelompok petani mencapai Rp 1 200.000.000 (tidak termasuk tanah dan bangunan). Nilai ini dapat menjadi asumsi besarnya investasi untuk pendirian Pipiltin Cocoa dengan produk keluaran yang sama yaitu cokelat batangan. Dengan demikian, berdasarkan informasi keuntungan dari analisis nilai tambah, Pipiltin dapat memprediksikan berapa besarnya kontribusi keuntungan terhadap investasi awal pada setiap periode produksinya.

Berdasarkan kedua jenis industri cokelat tersebut, faktor yang dapat dibedakan adalah jenis produk cokelat yang dihasilkan. Pemahaman yang sangat luas yang dimiliki pemilik Pipiltin Cocoa menjadikan produknya sangat mengutamakan kualitas cokelat yang dibuat dengan proses produksi yang cukup rumit. Hal ini tidak menjadi suatu keanehan mengapa harga jual cokelat Pipiltin sangat mahal. Selain itu, dari aspek tenaga kerja, Pipiltin menerima karyawan dengan pendidikan minimal SMK dengan keterampilan tata boga yang baik, sedangkan tenaga kerja yang bekerja di KUB Sibali Resoe adalah ratarata berpendidikan akhir SMA dan SMP, sedangkan pada Pipiltin Cocoa tenaga kerja adalah lulusan SMK dan tidak terdapat lulusan SMP. Dan untuk pemilik KUB Sibali resoe adalah berpendidikan Sarjana. Keadaan ini tidak jauh berbeda pada Pipiltin Cocoa, namun yang menjadi perbedaan adalah pemilik Pipiltin yaitu Ibu Tissa berpendidikan S2 serta terdapat rekan kerja. Selain itu, KUB Sibali Resoe pun tidak jarang mengajak karyawannya untuk mengikuti pelatihan-pelatihan layaknya Pipiltin Cocoa. Berdasarkan hasil perhitungan diatas, dapat disimpulkan bahwa industri pengolahan kakao menjadi produk cokelat batangan memberikan nilai yang cukup besar. Dari hasil perhitungan nilai tambah produsen dapat mengetahui keuntungan bersih yang diterima dari pengolahan biji kakao. Nilai keuntungan bersih ini dapat digunakan sebagai parameter dalam memperkirakan umur ekonomis bisnisnya. Dengan demikian, produsen mengetahui jangka waktu yang dibutuhkan perusahaan untuk menerima kembali investasi awal yang telah dikeluarkan.

Setelah dianalisis nilai tambah dan keuntungan yang diterima produsen pada uraian diatas, dengan mengkaitkan perhitungan dari nilai investasi yang ditanam dibagi dengan margin yang diterima perusahaan perbulannya, maka sebuah perusahaan cokelat seperti Pipiltin ini yang mengeluarkan biaya investasi lebih dari Rp 1 Miliar (tidak termasuk tanah dan bangunan) diperkirakan membutuhkan waktu dua tahun agar modal awal untuk penyediaan investasi alat dan mesin yang telah dikeluarkan dapat diterima kembali. Dua tahun merupakan jangka waktu yang tidak terlalu lama dalam sebuah bisnis, mengingat sejak memulai bisnis, pemilik perusahaan sudah dapat menikmati keuntungan. Hal ini berbeda dengan petani yang membutuhkan beberapa tahun agar dapat merasakan keuntungan dari penjualan buah kakaonya. Dengan demikian, prospek pengolahan biji kakao cukup memberikan harapan yang cerah. Permasalahan yang dihadapi adalah pada 
nilai investasi awal yang cukup besar dibutuhkan dalam pembangunan pada industri ini. Nilai tambah yang cukup besar diterima oleh Pipiltin ini bergantung pada beberapa aspek seperti pemilik yang memang mempunyai pengetahuan luas mengenai cokelat, mempunyai pendidikan yang tinggi, dan modal yang cukup, serta prinsip penjualan dengan mengutamakan loyalitas kualitas cokelat, tidak hanya melihat pada harganya. Faktor - faktor ini menjadi kekuatan pemilik Pipiltin untuk membangun sebuah budaya pada industri cokelat yang mengutamakan kualitas layaknya industri cokelat di negaranegara produsen cokelat dunia. Keteguhan prinsip pemasaran Pipiltin yang tidak hanya mengutamakan loyalitas konsumen namun loyalitas kualitas produk menjadi sebuah bargaining position bagi Pipiltin Cocoa tersendiri. Kemajuan Pipiltin Cocoa ini secara tidak langsung dalam jangka panjang akan memberikan kontribusi terhadap kesejahteraan petani kakao di Aceh dan Tabanan.

Pipiltin Cocoa dibangun dengan nilai investasi yang tidak rendah. Berdasarkan hasil wawancara, pemilik industri cokelat ini mengatakan bahwa pembelian alat dan mesin pengolah kakao ini sangat mahal dan tidak cukup dengan biaya Rp 1 Miliar. Oleh karena itu, dalam jangka pendek perusahaan akan memperluas pemasarannya untuk mendapatkan penerimaan yang lebih baik. Pembangunan industri cokelat akan lebih memiliki prospek yang cerah jika perusahaan memperbanyak jenis cokelat yang diproduksi dan meningkatkan jumlahnya. Volume cokelat yang besar akan mampu menekan biaya produksi. Oleh karena itu, rencana pemasaran Pipiltin Cocoa ke depan akan mencoba memasuki supermarket atau retailer.

Berdasarkan metode perhitungan nilai tambah Hayami, industri pengolahan kakao menjadi produk utama yaitu cokelat memberikan nilai tambah yang besar yaitu sebesar Rp 298.000 per kg biji kakao yang digunakan. Nilai tambah yang telah diperoleh memberikan pengaruh yang besar terhadap keuntungan produsen. Hal ini terlihat bahwa semakin besar nilai tambah yang dihasilkan maka produsen pun akan menerima keuntungan yang lebih besar.

Presentase keuntungan ini diperoleh berdasarkan perbandingan antara keuntungan dengan nilai tambahnya. Perbedaan hasil analisis nilai tambah dengan kedua metode diatas tidaklah signifikan. Dengan demikian, dapat disimpulkan bahwa industri pengolahan kakao menjadi produk cokelat batangan memberikan nilai yang cukup besar. Kelemahan dalam perhitungan nilai tambah menggunakan metode Hayami ini adalah perlunya menghitung beberapa variabel tambahan. Variabel-variabel tersebut seperti koefisien tenaga kerja dan adanya perhitungan untuk mengkonversi antara input per output. Hal ini berkaitan dengan langkah - langkah dalam perhitungan Hayami lebih jelas dan sistematis. Selain itu, berdasarkan hasil penelitian sebelumnya, beberapa kelebihan dari analisis nilai tambah Hayami menurut Nenni (2000) antara lain, 1. Dapat mengestimasi produktivitas produksi 2. Dapat mengestimasi balas jasa terhadap faktor-faktor 
produksi 3. Prinsip analisis ini dapat digunakan pula untuk selain subsistem pengolahan namun tidak pada sub sistem onfarm.

\section{SIMPULAN DAN SARAN \\ Simpulan}

Berdasarkan hasil dan pembahasan yang telah disajikan sebelumnya dapat disimpulkan bahwa nilai tambah dari produk chocolate bar adalah Rp 298.000 per kg biji kakao. Dengan demikian bahwa produk olahan biji kakao yang dihasilkan usaha menengah seperti Pipiltin Cocoa ini memberikan pendapatan yang cukup besar bagi pemilik usaha.

\section{Saran}

1. Berdasarkan hasil penelitian bahwa nilai tambah pada "Pipiltin Cocoa" memberikan nilai tambah yang cukup besar maka sangat disarankan kepada pemerintah dan stakeholder terkait dalam agribisnis kakao ini adalah agar lebih memfokuskan untuk menghasilkan produk-produk olahan kakao hingga menjadi cokelat dengan penggunaan cocoa butter asli atau cokelat converture dan mengggeser produksi sekunder yang masih berupa produk antara atau cokelat compound.

2. Penelitian ini memberikan suatu pelajaran bahwa harapan pembangunan industri cokelat yang dimulai dari petani atau perusahaan Indonesia membutuhkan banyak pihak yang dapat membantu, dalam hal ini terutama pemerintah. Kekuatan utama dalam mengolah biji kakao menjadi beragam produk turunan adalah faktor modal. Pemerintah berperan dalam mendukung petani khususnya dengan menyediakan alat dan mesin yang dibutuhkan karena mengingat pendirian industri pengolahan kakao membutuhkan investasi awal yang cukup besar. Selain itu, pabrik pengolahan kakao sebaiknya berlokasi tidak jauh dari lokasi perkebunan kakao. Hal ini diupayakan untuk mengurangi pengeluaran biaya produksi.

3. Dalam penelitian selanjutnya mengenai perhitungan nilai tambah pada pengolahan suatu komoditas pertanian, sangat direkomendasikan untuk menghitungnya dengan metode Hayami, mengingat beberapa keunggulan yang telah diuraikan diatas.

\section{DAFTAR PUSTAKA}

Asosiasi Industri Kakao Indonesia. 2012. Pabrik Cokelat JB Cocoa Beroperasi 2012. Surabaya: Surabaya Post.

Callebaut, Barry. 2012. Chocolate Consumption and Taste Preferences araind the World. Barry Callebaut Journal - 2012, Ecocomy International Barry Callebaut Internal.

Bradbear. 2006. Bees and their role in forest livelihoods. www.fao.org/docrep/015/i2462e/i 2462e00.pdf . Non-wood forest products No. 19, Rome pp. 32- 42 and FAO. 2006. Value-added products from.

Dilana, Indra Akbar. 2012. Pemasaran dan Nilai Tambah Biji Kakao di Kabupaten Madiun, Jawa Timur. 
Thesis, Sekolah Pasca Sarjana, IPB. Bogor.

Direktorat Jenderal Industri Agro dan Kimia. 2005. BUKU II - Analisis Penguatan dan Pengembangan Klaster Industri Agro dan Kimia. Jakarta: Kementerian Perindustrian.

Direktorat Pengembangan Usaha dan Investasi, Kementerian Pertanian. 2013. Sehat Dengan Romantis Cokelat. 2013. Jakarta: Kementerian Pertanian.

Direktorat Jenderal Pengolahan dan Pemasaran Hasil Pertanian. 2013. Laporan Akuntabilitas Instansi Pemerintah 2012. Direktorat Jenderal Pengolahan dan Pemasaran Hasil Pertanian, Jakarta: Kementerian Pertanian.

Ishak, Mira, dan Indriyanti Sudirman. 2000. Analisis Prospek dan Strategi Pengembangan Perusahaan pengolahan cokelat (Studi Kasus pada KUB Sibalie Resoe Luwu Utara).

Hayami, Y., T, Kawagoe, Y. Marooka, dan M. Siregar. 1987. Agricultural Marketing and Processing in Upland Java A Perspective From A Sunda Village. CGPRT Centre, Bogor.

International Cocoa Organization (2013). Production of Cocoa Beans. Accessed on: 17 November 2013. Available from:http://www.icco.org/about us/international-cocoa agreements/cat view/30- relateddocuments/46statisticsproduction.html
Kementrian Perindustrian. 2012. Laporan Kinerja Sektor Industri dan Kinerja Kementerian Perindustrian 2012. Jakarta: Kementerian Perindustrian.

Kementerian Pertanian. 2013. Laporan Data Kinerja Kementerian Pertanian 2004-2012. Jakarta: Kementerian Pertanian.

Nurhayati, Popong. 2006. Nilai Tambah Produk Olahan Perikanan Pada Industri Perikanan Traoisonal di DKI Jakarta. Buletin Ekonomi Perikanan Vol. V. No.2

Pusat Data dan Informasi Pertanian Kementrian Pertanian. 2011. Statistik Pertanian 2011. Jakarta: Pusat Data dan Informasi Pertanian Kementerian Pertanian.

Pusat Data dan Informasi Kementrian Perindustrian._. Laporan Ekspor Hasil Industri Pengolahan. Jakarta: Pusat Data dan Informasi Kementerian Perindustrian.

Pusat Penelitian Kopi dan Kakao Indonesia. 2013. 100 Tahun Pusat Penelitian Kopi dan Kakao Indonesia. Jember: Pusat Penelitian Kopi dan Kakao Indonesia.

Rifin, Amzul. 2012. Impact of Export Tax Policy on Cocoa Farmers and Supply Chain. SEADI Discussion Paper Number one. The United States Agency for International Development.

Sinaga, Merika Sondang. 2008. Analisis Nilai Tambah dan Dayasaing serta Dampak Kebijakan Pemerintah terhadap Industri Tempe di Kabupaten Bogor (Kasus: Desa Citeureup, Kecamatan Citeureup). 
[Skripsi]. Bogor (ID) : Institut Pertanian Bogor.

Suherman, Astriani. 2012. Analisis Nilai Tambah Kayu Mahoni Sebagai Bahan Baku Kerajinan Boneka Whimsy Di CV ATLAS Kota Tasikmalaya. [Skripsi]. Bogor (ID) : Institut Pertanian Bogor.

Sukandar, Nenni WH. 2000. Analisis Nilai Tambah dan Prospek Pengembangan Industri Pengolahan Kayu (Perbandingan Metode M. Dawam Rahardjo dan Hayami). [Skripsi]. Bogor (ID) : Institut Pertanian Bogor.

Swisscontact. 2012. Coklat Kakao Cocoa. State Secretariat for Economic Affairs SECO.

Syadullah, Makmun. 2012. Dampak Kebijakan Bea Keluar Terhadap Ekspor dan Industri Pengolahan Kakao. Buletin Ilmiah Litbang Perdagangan, Vol. 6 No. 1, Juli 2012.

The Times 100. 2012. Creating a Sustainable Chocolate Industry. www.bcca.org.uk

Tim INDEF (Institut For Development of Economics and Finance). 2011. Outlook Industri 2012 “ Strategi Percepatan dan Perluasan Agroindustri”. Jakarta: Kementrian Perindustrian.

World Cocoa Foundation. 2012. Cocoa Market Update. www.worldcocoa.org
UNCTAD secretariat. 2008. Cocoa Study: Industry Structures and Competition. United Nations Conference on Trade and Development, New York and Geneva.UNCTAD/DITC/COM/20 $08 / 1$. 
Lampiran 1. Produksi Biji Kakao Dunia ( 000 Ton)

\begin{tabular}{lrrr}
\hline & $\mathbf{2 0 1 0} / \mathbf{2 0 1 1}$ & $\mathbf{2 0 1 1} / \mathbf{2 0 1 2}$ & $\mathbf{2 0 1 2} / \mathbf{2 0 1 3}$ \\
\hline Afrika & $\mathbf{3 2 2 4}$ & $\mathbf{2 9 1 9}$ & $\mathbf{2 8 7 6}$ \\
Kamerun & 229 & 207 & 225 \\
Pantai Gading & 1511 & 1486 & 1480 \\
Ghana & 1025 & 879 & 850 \\
Nigeria & 240 & 235 & 230 \\
Lainnya & 220 & 113 & 91 \\
\hline Amerika & $\mathbf{5 6 1}$ & $\mathbf{6 4 2}$ & $\mathbf{5 9 5}$ \\
Brazil & 200 & 220 & 185 \\
Ecuador & 161 & 190 & 185 \\
Lainnya & 201 & 232 & 225 \\
\hline Asia dan Oceania & $\mathbf{5 2 6}$ & $\mathbf{5 2 0}$ & $\mathbf{5 1 5}$ \\
Indonesia & 440 & 450 & 430 \\
Papua New Guinea & 48 & 39 & 45 \\
Lainnya & 39 & 32 & $\mathbf{4 0}$ \\
\hline Total Dunia & $\mathbf{4 3 1 2}$ & $\mathbf{4 0 8 2}$ & $\mathbf{3 9 8 6}$ \\
\hline Sumber : ICCO 2013 & & &
\end{tabular}

Lampiran 2 Grinding (Pengolahan) Biji Kakao ( 000 Ton)

\begin{tabular}{lrrr}
\hline & $\mathbf{2 0 1 0} / \mathbf{2 0 1 1}$ & $\mathbf{2 0 1 1} / \mathbf{2 0 1 2}$ & $\mathbf{2 0 1 2} / \mathbf{2 0 1 3}$ \\
\hline Eropa & $\mathbf{1 6 2 4}$ & $\mathbf{1 5 2 1}$ & $\mathbf{1 5 7 5}$ \\
Jerman & 439 & 407 & 400 \\
Belanda & 540 & 500 & 530 \\
Lainnya & 646 & 614 & 645 \\
\hline Afrika & $\mathbf{6 5 8}$ & $\mathbf{7 1 7}$ & $\mathbf{7 5 5}$ \\
Pantai Gading & 361 & 431 & 460 \\
Ghana & 230 & 212 & 225 \\
Lainnya & 67 & 74 & 70 \\
\hline Amerika & $\mathbf{8 6 1}$ & $\mathbf{8 4 5}$ & $\mathbf{8 7 8}$ \\
Brazil & 230 & 212 & 225 \\
Ecuador & 67 & 74 & 70 \\
Lainnya & 221 & 216 & 225 \\
\hline Asia dan Oceania & $\mathbf{7 9 5}$ & $\mathbf{8 7 3}$ & $\mathbf{8 4 5}$ \\
Indonesia & 190 & 270 & 255 \\
Papua New Guinea & 305 & 297 & 293 \\
Lainnya & 299 & 307 & 298 \\
\hline Total Dunia & $\mathbf{3 9 3 8}$ & $\mathbf{3 9 5 6}$ & $\mathbf{4 9 5 6}$ \\
\hline
\end{tabular}

Keterangan: * Estimasi

Sumber : ICCO 2013 
Lampiran 3. Perhitungan Analisis Nilai Tambah

\begin{tabular}{ll}
\hline \multicolumn{1}{c}{ Variabel } & Nilai \\
\hline I Output, Input, dan Harga & \\
1. Output/total produksi (kg/periode) & 1 \\
2. Input/bahan baku (kg/periode) & 2 \\
3. Tenaga kerja (HOK/periode) & 3 \\
4. Faktor Konversi & $4=1 / 2$ \\
5. Koefisien Tenaga Kerja (HOK/kg) & $5=3 / 2$ \\
6. Harga output (Rp) & 6 \\
7. Upah tenaga kerja (Rp/HOK) & 7 \\
\hline
\end{tabular}

II Penerimaan dan Keuntungan

8. Harga bahan baku (Rp/kg) 8

9. Sumbangan input lain (Rp/kg) 9

10. Nilai output $(\mathrm{Rp} / \mathrm{kg})$

a. Nilai tambah (Rp/kg)

b. Rasio nilai tambah (\%)

11; a. Pendapatan tenaga kerja ( $\mathrm{Rp} / \mathrm{kg})$

9

b. Pangsa tenaga kerja (\%)

12 a. Keuntungan (Rp/kg)

$10=4 \times 6$

$11 \mathrm{a}=10-9-8$

$11 \mathrm{~b}(\%)=11 \mathrm{a} / 10 \times 100 \%$

$12 \mathrm{a}=5 \times 7$

$12 \mathrm{~b}(\%)=(12 \mathrm{a} / 11 \mathrm{a}) \times 100 \%$

b. Tingkat keuntungan (\%)

$13 \mathrm{a}=11 \mathrm{a}-12 \mathrm{a}$

$13 b(\%)=(13 a / 11 a) \times 100 \%$

\section{Balas Jasa Pemilik Faktor Produksi}
13. Marjin (Rp/kg)
$14=10-8$
14 a. Pendapatan tenaga kerja (\%)
b. Sumbangan input lain (\%)
$14 \mathrm{a}(\%)=(12 \mathrm{a} / 14) \times 100 \%$
c. Keuntungan pengusaha (\%)
$14 \mathrm{~b}(\%)=(9 / 14) \times 100 \%$
$14 \mathrm{c}(\%)=(13 \mathrm{a} / 14) \times 100 \%$

Sumber : Hayami et al1987

\section{Lampiran 4. Proporsi Hasil Nilai Tambah Pengolahan Biji Kakao Menjadi} Produk Antara

\begin{tabular}{lccrr}
\hline \multicolumn{1}{c}{ Variabel } & Pasta & Lemak & Bubuk & $\begin{array}{c}\text { Bubuk dan } \\
\text { Lemak }\end{array}$ \\
\hline $\begin{array}{l}\text { Proporsi hasil per } \\
100 \text { kg bahan baku }\end{array}$ & 75 & 45 & 30 & 75 \& 30 \\
$\begin{array}{l}\text { (kg) } \\
\text { Nilai Tambah }\end{array}$ & 16347 & 5847 & 2847 & 29847 \\
$(\mathrm{Rp} / \mathrm{kg})$ & & & & \\
\hline Sumber: Dilana (2012) & & & &
\end{tabular}


Lampiran 5. Hasil Analisis Nilai Tambah Pada Pengolahan Biji Kakao Menjadi Chocolate Bar dengan Metode Hayami

\begin{tabular}{lr}
\hline Variabel & Nilai \\
\hline I Output, Input, dan Harga & 26 \\
1. Output/total produksi (kg/periode) & 30 \\
2. Input/bahan baku (kg/periode) & 3 \\
3. Tenaga kerja (HOK/periode) & 0,87 \\
4. Faktor Konversi & 0,3 \\
5. Koefisien Tenaga Kerja (HOK/kg) & 400000 \\
6. Harga output (Rp) & 67000 \\
7. Upah tenaga kerja (Rp/HOK) & \\
\hline II Penerimaan dan Keuntungan & 44000 \\
8. Harga bahan baku (Rp/kg) & 6000 \\
9. Sumbangan input lain (Rp/kg) & 348000 \\
10. Nilai output (Rp/kg) & 298000 \\
a. Nilai tambah (Rp/kg) & 86,63 \\
$\quad$ b. Rasio nilai tambah (\%) & 26800 \\
11; a. Pendapatan tenaga kerja (Rp/kg) & 8,99 \\
$\quad$ b. Pangsa tenaga kerja (\%) & 271200 \\
12 a. Keuntungan (Rp/kg) & 91 \\
$\quad$ b. Tingkat keuntungan (\%) & \\
\hline III Balas Jasa Pemilik Faktor Produksi & 39,97 \\
13. Marjin (Rp/kg) & 304000 \\
14 a. Pendapatan tenaga kerja (\%) & 8,82 \\
$\quad$ b. Sumbangan input lain (\%) & 1,97 \\
c. Keuntungan pengusaha (\%) & \\
\hline
\end{tabular}

